\title{
The Prevalence of Plasmid-Mediated Quinolone Resistance Genes among CTX-M-14 Producing Escherichia coliStrains Isolated from a University Hospital in the Chungcheong Province
}

\author{
Ji Youn Sung \\ Department of Biomedical Laboratory Science, Far East University, Eumseong 27601, Korea
}

\section{충청지역에 위치한 일개의 대학병원에서 분리된 CTX-M-14형 $\mathrm{ESBL}$ 생성 대장균을 대상으로 $\mathrm{PMQR}$ 유전자 빈도조사}

성지연

\begin{abstract}
Recently, there has been a considerable increase in the prevalence of CTX-M type extended-spectrum $\beta$-lactamase (ESBL)-producing E. coli isolates worldwide, including Korea. To investigate the $\mathrm{ESBL}$ genes in the $E$. coli strains isolated from a university hospital in the Chungcheong area, a study was conducted using PCR amplification and nucleotide sequence analysis of the amplified products to detect the plasmid mediated quinolone resistance (PMQR) genes in ESBL producing E. coli isolates. The number of $\mathrm{CTX}-\mathrm{M}-14$ producing isolates was 25 (16.0\%) isolates, and of them, 9 (5.8\%) isolates also produced CTX-M-15. All CTX-M type ESBL producing $E$. coli isolates showed resistance to cefotaxime. Twelve (48\%) CTX-M type ESBL producing E. coli isolates contained the PMQR genes, 8 contained qnrS1, and 8 contained $\operatorname{aac}\left(6^{\prime}\right)-I b-c r$. Four isolates harbored both qnrS1 and $a a c\left(6^{\prime}\right)-I b-c r$ genes. In our study, we confirmed that the plasmid mediated antimicrobial resistant determinants-the ESBL and PMQR genes - were distributed in the $E$. coli isolates. To prevent further spreading of the resistant genes among the $E$. coli isolates, consistent effort is required to investigate and monitor the resistant genes.
\end{abstract}

Key words: CTX-M type, Extended-spectrum $\beta$-lactamase, Plasmid mediated quinolone resistance, E. coli

This is an Open Access article distributed under the terms of the Creative Commons Attribution Non-Commercial License (http://creativecommons.org/licenses/by-nc/4.0) which permits unrestricted non-commercial use, distribution, and reproduction in any medium, provided the original work is properly cited.

Copyright (c) 2016 The Korean Society for Clinical Laboratory Science. All rights reserved.
Corresponding author: Ji Youn Sung Department of Biomedical Laboratory Science, Far East University, Wangjang-ri, Gamgok-myeon, Eumseong 27601, Korea Tel: 82-43-879-3668 Fax: 82-43-880-3876 E-mail: azaza72@naver.com

Received: July 30, 2016 Revised: August 29, 2016 Accepted: September 5, 2016
서 론

대부분의 대장균(Escherichia coli)은 사람과 동물의 장내에 정 상균무리로 존재하지만 때로는 사람에게 심한 설사를 동반한 질환 을 일으키기도 한다. 이러한 대장균은 병독성에 따라 크게 diffusely adherent $E$. coli (DAEC), enteroaggregative $E$. coli (EAEC), enterohemorrhagic E. coli (EHEC), enteroinvasive $E$. coli (EIEC), enteropathogenic E. coli (EPEC), 및 enterotoxigenic E. coli (ETEC)등의 6개의 그룹으로 분류되는데 이 중 ETEC는 개발 도상국가의 어린이와 여행자에게 설사를 일으키며 $\mathrm{EAEC}$ 는 개발 
도상국가 및 선진국가에서 설사질환을 일으키는 원인균으로 작용 한다[1].

이러한 대장균을 포함한 장내 병원성 세균에 의한 감염증 치료 를 위해 3 세대 cephalosporins 및 fluoroquinolones이 일반적으 로 사용되어 왔다. 그러나 대장균을 비롯한 장내세균과에 속한 세 균들은 빈번하게 extended-spectrum $\beta$-lactamase (ESBL)를 생 성하여 penicillins, cephalosporins, 및 monobactams등 $\beta$-lactam 계열의 항균제에 내성을 나타내게 되었다. 특히 Ambler class A에 속하는 CTX-M형 ESBL은 최근 들어 설사를 유발하는 대장균들 사 이에 빠르게 확산되었고 전 세계적으로 대장균에서 가장 빈번하게 검출되는 ESBL이 되었다[2]. CTX-M형 ESBL은 최근까지 약 50여 종 이상이 보고되었는데 아미노산 서열에 기초하여 CTX-M-1like (CTX-M-1, -3, -10, -11, -12, -15, -28, 및 FEC-1), CTX-M-2 like (CTX-M-2, -4, -5, -6, -7, -20, 哭 TOHO-1), CTX-M-8 like (CTX-M-8), CTX-M-9 like (CTX-M-9, -13, -14,-16, -17, -19, $-21,-24,-27$ 및 TOHO-2), 및 CTX-M-25등 크게 5개의 그룹으 로 분류되고 있다[3]. 국내에서도 1990년대 후반 까지는 장내세균 에서 분리되는 주된 ESBL형은 TEM-52, SHV-2a, 및 SHV-12형이 었으나 최근 들어 CTX-M형이 그리고 그 중에서도 특히 CTX-M-14 및 CTX-M-15형이 가장 빈번하게 분리되고 있다[4].

한편 CTX-M형을 포함한 다양한 ESBL 유전자는 플라스미드, transposons 및 integrons 같은 mobile genetic elements에 의해 세균 사이에 전파되는데 이는 ESBL 생성 세균의 광범위한 확산을 유발하는 원인이 된다[2]. 특히 mobile genetic elements는 ESBL 유전자뿐 아니라 다양한 항균제 내성 유전자를 운반할 수 있는데 그 대표적인 것이 plasmid mediated quinolone resistance (PMQR) 유전자이다. 대장균이 PMQR 유전자를 mobile genetic elements를 통해 획득할 경우 quinolone 계열의 항균제에도 내성 을 나타낼 수 있게 된다[5]. Quinolone 계열의 항균제는 1960년대 부터 세균감염을 치료하기 위해 보편적으로 사용되어온 항균제이 나 최근 quinolone 계열의 항균제에 내성을 나타내는 장내세균이 광범위하게 확산되고 있다. 세균이 quinolone 계열의 항균제에 내 성을 나타내는 주된 기전은 염색에 위치한 DNA gyrase 및 topoisomerase IV 유전자의 돌연변이, 유출펌프의 과량발현, 및 외막 포린단백 감소 등 염색체 상의 돌연변이에 의한다[6]. 그러나 최근 $q n r A, q n r B, q n r S$, $a a d(6)-I b-c r$, 및 $q e p A$ 등과 같은 PMQR 유전자가 장내세균과에 속한 세균들에서 빈번하게 검출되고 있다 [7]. PMQR 유전자를 획득한 세균은 quinolone 계열의 항균제가 DNA gyrase 및 topoisomerase IV의 기능을 억제하는 것을 방해 하거나, quinolone 계열의 항균제를 변형시키거나 세포 밖으로 능 동적으로 유출시킴으로써 내성을 나타내게 된다[8].
세균간의 mobile genetic elements를 매개로 한 ESBL 및 $\mathrm{PMQR}$ 유전자들의 수평적 확산은 다제내성 세균의 출현을 야기할 뿐 아니라 다제내성 세균을 빠르게 확산시킬 수 있어 문제가 되고 있다. 본 연구에서는 충청지역에 위치한 일개의 대학병원에서 분리 된 대장균을 대상으로 $\mathrm{ESBL}$ 의 생성여부와 그 유전형을 조사하였으 며 아울러 $\mathrm{ESBL}$ 생성 대장균 사이에 확산되어 있는 $\mathrm{PMQR}$ 유전자 의 빈도 및 그 종류를 확인하였다. 또한 repetitive extragenic palindromic sequence-based PCR (REP-PCR)을 이용하여 $\mathrm{ESBL}$ 생성 대장균의 역학적 연관성을 조사하였다. REP-PCR은 pulsed-field gel electrophoresis (PFGE)와 같이 세균감염 확산 의 역학적 연구를 위해 광범위하게 사용되는 분자생물학적 방법이 다. PFGE는 고도의 분별력을 가지고 있어 일반적으로 gold standard로 불리지만 시간과 비용이 많이 소요되는 단점이 있으며 고도의 숙련도가 필요하다. 이에 비해 REP-PCR은 아주 간단하지 만 강력한 molecular typing 방법이어서 최근 많이 이용되고 있다 [9]. 본 연구에서는 REP-PCR을 이용하여 ESBL생성 대장균의 clonality를 분석하였는데 이 결과는 다제내성 세균의 출현 및 전파 양상을 제고하고 확산 방지책을 마련하는데 필요한 기초자료가 될 것으로 사료된다.

\section{재료 및 방법}

\section{1. 균주의 수집}

2013년 8월부터 2014년 6월까지 충청지역에 위치한 일개의 대 학병원에 의뢰된 임상검체로부터 분리된 대장균 156 균주를 대상 으로 하였다. 항균제 내성에 상관없이 분리된 순서대로 균주를 수 집하였으며, 동일 환자에서 반복 분리된 균주는 수집대상에서 제외 하였다. 분리된 균주를 VITEK GNI card (bioMerieux Vitek Inc., Hazelwood, MO, USA)를 이용하여 생화학적 방법으로 동정 하였다.

\section{ESBL 생성 확인시험 및 항균제 감수성 시험}

대장균이 ESBL을 생성하는지 알아보기 위해 Clinical and Laboratory Standards Institute (CLSI) 지침에 따라 ESBL 생성 확 인시험을 시행하였다[10]. Mueller-Hinton 한천 배지(Difco, Cockeysville, MD, USA)에 McFarland 0.5 탁도의 균액을 바른 후 cefotaxime (BBL, Cockeysville, MI, USA, $30 \mu \mathrm{g}$ )과 cefotaxime/clavulanic acid (CTC) (BBL, 30/10 $\mu$ ), ceftazidime (BBL, $30 \mu \mathrm{g}$ )과 ceftazidime/clavulanic acid (CZC) (BBL, 30/10 $\mu \mathrm{g}$ ) 디 스크를 놓고 $35^{\circ} \mathrm{C}$ 에서 $16 \sim 18$ 시간 배양 후 억제대를 측정하여 CTC 또는 CZC에 의한 억제대가 cefotaxime과 ceftazidime에 의 한 억제대 보다 $5 \mathrm{~mm}$ 이상 클 경우 $\mathrm{ESBL}$ 생성 양성 균주로 판정하 
였다.

$\mathrm{ESBL}$ 생성 확인시험에서 양성으로 판정된 균주를 대상으로 CLSI 지침에 따라 ampicillin cefotaxime, ceftazidime, tobramycin, amikacin, gentamicin, nalidixic acid, ciprofloxacin, 및 levofloxacin (BBL)에 대한 감수성을 Mueller-Hinton 한천 (Difco)을 사용하여 디스크 확산법으로 확인하였다[8]. 정도관리 를 위해서 Escherichia coli ATCC 25922를 동시에 시험하여 허용 범위내에 있는지를 확인하였다.

\section{3. 항균제 내성유전자 검출}

$\mathrm{ESBL}$ 생성 확인시험에서 양성으로 판정된 균주를 대상으로 $\mathrm{ESBL}$ 유전자의 유전형 확인과 $\mathrm{PMQR}$ 유전자의 검출을 위해 기존 의 시발체(Table 1)를 사용하여 중합효소연쇄반응을 수행하였다 [11-14]. 대상 균주를 brain heart infusion broth (Difco) 에 접종 하여 $37^{\circ} \mathrm{C}$ 에서 하룻밤 진탕배양 한 후 배양액으로부터 DNA 추출 시약(솔젠트, 대전, 한국)을 사용하여 chromosomal DNA를 추출 하였다. DNA 추출액( $5 \mu \mathrm{L}), 10 \times$ Taq buffer $(2.5 \mu \mathrm{L}), 10 \mathrm{mM}$ $\mathrm{dNTP}$ mix $(0.5 \mu \mathrm{L})$, primer 각 $10 \mathrm{pmol}, 0.7 \mathrm{U}$ Taq DNA 중합효소 (솔젠트) 및 증류수를 혼합하여 총 부피 $25 \mathrm{~mL}$ 의 반응용액을 만들 었다. Gene Amp PCR System 9600 (Perkin-Elmer Cetus Corp., Norwalk, CT, USA)으로 $95^{\circ} \mathrm{C}$ 에서 5 분간 반응시킨 후, $95^{\circ} \mathrm{C}$ 에서 20 초, $59^{\circ} \mathrm{C}$ 에서 40 초, $72^{\circ} \mathrm{C}$ 에서 30 초씩 30 회 증폭 반응시키고, $72^{\circ} \mathrm{C}$ 에서 5 분간 연장 반응시켰다. 각각의 $\mathrm{PCR}$ 생산물을 ethidium bromide가 포함된 1\% agarose gel에서 40 분간 전기영동하여 band를 확인하였다. 증폭산물을 DNA 추출시약(솔젠트)로 분리 후, BigDye Terminator Cycle Sequencing Kit (PE Applied Biosystems, Foster City, CA, USA)와 ABI PRISM 3730xl DNA analyzer (PE Applied Biosystems)를 이용하여 염기 서열을 분석 하였다.

\section{Repetitive extragenic palindromic sequence-based $\mathrm{PCR}$ (REP-PCR)을 이용한 ESBL생성 대장균의 역학적 연관성 조사}

ESBL 유전자를 포함하고 있는 균주를 대상으로 REP1 (5'IIIGCGCCGICATCAGGC-3')과 REP2 (5'-ACGTCTTATCAGGCCTAC-3')로 명명된 장내세균의 반복 서열을 시발체로하여 REP-PCR을 수행하였다[15]. 증폭반응은 DNA 추출액 $(5.0 \mu \mathrm{L})$, $10 \times$ Taq buffer $(5.0 \mu \mathrm{L}), 10 \mathrm{mM} \mathrm{dNTP} \mathrm{mix}(1.0 \mu \mathrm{L})$, primer 각 $20 \mathrm{pmol}, 1.4 \mathrm{U} \mathrm{Taq}$ DNA polymerase (솔젠트) 및 증류수를 혼합 하여 $50 \mu \mathrm{L}$ 의 혼합액으로 시행하였다. Gene Amp PCR System 9600 (Perkin-Elmer Centus)으로 $95^{\circ} \mathrm{C}$ 에서 5 분간 반응시킨 후, $90^{\circ} \mathrm{C}$ 에서 40 초, $42^{\circ} \mathrm{C}$ 에서 1 분, $68^{\circ} \mathrm{C}$ 에서 7 분씩 35 회 증폭 반응시 키고, $68^{\circ} \mathrm{C}$ 에서 15 분간 연장 반응시켰다. 증폭산물 $(10 \mu \mathrm{L})$ 은 ethidium bromide가 포함된 2\% agarose gels에 전기영동 한 후

Table 1. Oligonucleotides used in this study for detection of plasmid mediated antimicrobial resistant genes

\begin{tabular}{|c|c|c|c|c|}
\hline Group & Primer & Sequence $\left(5^{\prime}-3^{\prime}\right)$ & Gene & Reference \\
\hline \multirow[t]{12}{*}{ ESBL genes } & TEM-F & ATAAAATTCTTGAAGACGAAA & blateM & [11] \\
\hline & TEM-R & GACAGTTACCAATGCTTAATCA & & \\
\hline & SHV-F & GGGTTATTCTTATTTGTCGC & blashv & {$[11]$} \\
\hline & SHV-R & TTAGCGTTGCCAGTGCTC & & \\
\hline & CTX-M-1F & GACGATGTCACTGGCTGAGC & blactX-м1-like & {$[11]$} \\
\hline & $C T X-M-1 R$ & AGCCGCCGACGCTAATACA & & \\
\hline & $\mathrm{CTX}-\mathrm{M}-2 \mathrm{~F}$ & GCGACCTGGTTAACTACAATCC & blactX-м2-like & [11] \\
\hline & CTX-M-2R & CGGTAGTATTGCCCTTAAGCC & & \\
\hline & $\mathrm{CTX}-\mathrm{M}-8 \mathrm{~F}$ & AGACCTGATTAACTACAATCCCATTA & blactx-м8-like & {$[11]$} \\
\hline & $\mathrm{CTX}-\mathrm{M}-8 \mathrm{R}$ & АСTTTCTGCCTTCTGCTCTGGC & & \\
\hline & CTX-M-9F & GCTGGAGAAAAGCAGCGGAG & blactх-м9-like & {$[11]$} \\
\hline & CTX-M-9R & GTAAGCTGACGCAACGTCTG & & \\
\hline \multirow[t]{10}{*}{ Quinolone resistant genes } & QnrA-F & AGAGGATTTCTCACGCCAGG & qnrA1 to qnrA6 & [12] \\
\hline & QnrA-R & TGCCAGGCACAGATCTTGAC & & \\
\hline & QnrB-F & GGMATHGAAATTCGCCACTG & qnrB1 to $q n r B 6$ & [12] \\
\hline & QnrB-R & TTTGCYGYYCGCCAGTCGAA- & & \\
\hline & QnrS-F & GCAAGTTCATTGAACAGGGT & qnrS1 to $q n r S 2$ & {$[12]$} \\
\hline & QnrS-R & TCTAAACCGTCGAGTTCGGCG & & \\
\hline & $A A C\left(6^{\prime}\right)-I b F$ & TGACCAACAGCAACGATTCC & $\operatorname{aac}(6)-1 b \mathrm{cr}$ & [13] \\
\hline & $A A C\left(6^{\prime}\right)-I b R$ & TTAGGCATCACTGCGTGTTC & & \\
\hline & QepA-F & GCAGGTCCAGCAGCGGGTAG & qepA & {$[14]$} \\
\hline & QepA-R & CTTCCTGCCCGAGTATCGTG & & \\
\hline
\end{tabular}

Abbreviations: $F$, sense primer; $R$, antisense primer. 
BioDoc-14 Imagingsystem (UVP, Cambridge, UK)을 이용하여 분석하였다. Band의 강도와 상관없이 band의 분자량과 개수로 각 균주를 비교하며, 두 개 이상의 밴드 차이가 있으면 역학적 상관관 계가 없는 것으로 판단하였다[15].

\section{결 과}

\section{ESBL 생성균주의 분리 및 항균제 감수성 양상}

임상검체에서 분리된 대장균 156균주를 대상으로 CLSI 디스크 확산법에 의한 ESBL 생성 확인시험을 시행한 결과 $20.5 \%$ 에 해당하 는 32 균주가 양성반응을 보였다. 양성 결과를 보인 32 균주를 대상 으로 Ambler class A에 속하는 ESBL (bla $a_{\mathrm{TEM}}$, blas a $_{\mathrm{SH}}$, 및 bla $a_{\mathrm{CTX}} \mathrm{M}$ ) 유전자 검출을 위한 중합효소연쇄반응을 시행한 결과 blactX-M9-1ike 를 검출하기 위한 반응에서 25 균주가 양성반응을 보였다. 그리고 25균주 중 9균주는 blacTX-M1-like 를 검출하기 위한 반응에도 동시에 양성반응을 나타냈다. 유전자의 유전형을 결정하기 위해 염기서열 분석을 실시한 결과 blactX-M9-like 반응에서 생성된 PCR 산물은 모 두 blactX-M-14로, 그리고 blactx-M1-like 반응에서 생성된 PCR 산물
은 모두 blacTX-M-15로 확인되었다(Table 2). 한편 blactX-M1-like 및

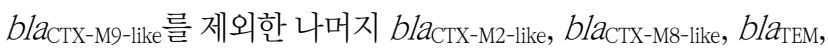
및 blasHV를 검출하기 위한 중합효소연쇄반응에서는 PCR 산물이 하나도 생성되지 않았다.

CTX-M-14 및 CTX-M-15를 생성하는 대장균 25균주를 대상 으로 항균제 감수성 시험을 한 결과 ceftazidime에 대한 감수성이 $76.0 \%$ 로 가장 높았고 gentamicin (48.0\%)이 그 다음으로 높았다. 한편 본 연구에서 검사한 9종류의 항균제 중 ceftazidime 및 gentamicin을 제외한 7종류의 항균제에 대해서는 모든 균주가 $40 \%$ 이하의 낮은 감수성률을 보였다(Table 3).

\section{2. $\mathrm{PMQR}$ 내성 유전자 검출}

CTX-M형 ESBL 유전자를 포함하고 있는 대장균 25균주를 대상 으로 PMQR 유전자 (qnrA, qnrB, qnrS, aac(6)-Ib-cr, 및 qepA) 의 빈도를 조사하기 위해 중합효소연쇄반응을 수행한 결과 12 균주 (48\%)가 PMQR 유전자를 가지고 있는 것으로 나타났다. $q n r S$ 유전 자를 검출하기 위한 반응에서 8균주(32\%) 그리고 $a a d(6)-I b-C r$ 유전자를 검출하기 위한 반응에서 8 균주 $32 \%$ )가 각각 양성반응을

Table 2. Characterizations of 25 CTX-M type ESBL producing Escherichia coli

\begin{tabular}{|c|c|c|c|c|c|c|c|c|c|c|c|c|c|c|}
\hline \multirow{2}{*}{ Isolates } & \multirow{2}{*}{ Specimens } & \multicolumn{4}{|c|}{ Antimicrobial resistance genes } & \multicolumn{9}{|c|}{ Antimicrobial susceptibilities } \\
\hline & & \multicolumn{2}{|c|}{ ESBL genes } & \multicolumn{2}{|c|}{ PMQR gens } & \multirow{2}{*}{$\frac{A M}{R}$} & \multirow{2}{*}{$\frac{C T X}{R}$} & \multirow{2}{*}{$\frac{C A Z}{S}$} & \multirow{2}{*}{$\begin{array}{c}\text { NN } \\
R\end{array}$} & \multirow{2}{*}{$\begin{array}{c}A K \\
R\end{array}$} & \multirow{2}{*}{$\frac{C N}{1}$} & \multirow{2}{*}{$\begin{array}{c}\text { NA } \\
R\end{array}$} & \multirow{2}{*}{$\frac{C I P}{R}$} & \multirow{2}{*}{$\begin{array}{r}\text { LEV } \\
R\end{array}$} \\
\hline CD1 & Urine & blactX-M14 & & & qnrS1 & & & & & & & & & \\
\hline $\mathrm{CD} 2$ & Urine & blactX-м14 & & & qnrS1 & $\mathrm{R}$ & $\mathrm{R}$ & $\mathrm{S}$ & $\mathrm{S}$ & $\mathrm{S}$ & $\mathrm{S}$ & $\mathrm{R}$ & $\mathrm{R}$ & $\mathrm{R}$ \\
\hline CD3 & Urine & blactX-м14 & blactX-м15 & $a a c 6-1 b-c r$ & qnrS1 & $\mathrm{R}$ & $\mathrm{R}$ & $\mathrm{R}$ & $\mathrm{R}$ & $\mathrm{R}$ & I & $\mathrm{R}$ & $\mathrm{R}$ & $\mathrm{R}$ \\
\hline CD5 & Body Fluid & blactX-M14 & & & & $\mathrm{R}$ & $\mathrm{R}$ & $\mathrm{R}$ & $\mathrm{S}$ & $S$ & $\mathrm{~S}$ & $\mathrm{R}$ & $\mathrm{R}$ & $\mathrm{R}$ \\
\hline CD7 & Urine & blactX-м14 & & & qnrS1 & $\mathrm{R}$ & $\mathrm{R}$ & $\mathrm{S}$ & $\mathrm{S}$ & I & $\mathrm{S}$ & $\mathrm{R}$ & $\mathrm{S}$ & $\mathrm{S}$ \\
\hline CD9 & Urine & blactX-м14 & blactX-м15 & $a a c 6-1 b-c r$ & qnrS1 & $\mathrm{R}$ & $\mathrm{R}$ & $S$ & $S$ & $S$ & S & 1 & $R$ & 1 \\
\hline CD11 & Sputum & blactX-M14 & blactX-M15 & $a a c 6-1 b-c r$ & & $\mathrm{R}$ & $\mathrm{R}$ & $\mathrm{R}$ & $\mathrm{R}$ & I & $\mathrm{R}$ & $\mathrm{R}$ & $\mathrm{R}$ & $\mathrm{R}$ \\
\hline CD17 & Urine & blactX-м14 & blactX-M15 & & & $\mathrm{R}$ & $\mathrm{R}$ & $\mathrm{S}$ & $\mathrm{R}$ & I & $\mathrm{R}$ & 1 & $\mathrm{~S}$ & $\mathrm{~S}$ \\
\hline CD19 & Urine & blactX-M14 & & $a a c 6-1 b-c r$ & qnrS1 & $\mathrm{R}$ & $\mathrm{R}$ & S & $\mathrm{S}$ & I & $S$ & $\mathrm{R}$ & $\mathrm{R}$ & $\mathrm{R}$ \\
\hline CD20 & Urine & blactX-м14 & blactX-м15 & $a a c 6-1 b-c r$ & & $\mathrm{R}$ & $\mathrm{R}$ & S & $\mathrm{R}$ & I & $\mathrm{R}$ & $\mathrm{S}$ & $S$ & $\mathrm{~S}$ \\
\hline CD24 & Blood & blactX-м14 & & $a a c 6-1 b-c r$ & qnrs1 & $R$ & $\mathrm{R}$ & $\mathrm{R}$ & $\mathrm{S}$ & $S$ & $\mathrm{~S}$ & I & $R$ & I \\
\hline CD27 & Blood & blactX-M14 & & & & $\mathrm{R}$ & $\mathrm{R}$ & S & $S$ & I & $S$ & $\mathrm{R}$ & $\mathrm{R}$ & $\mathrm{R}$ \\
\hline CD33 & Urine & blactX-м14 & & & & $\mathrm{R}$ & $\mathrm{R}$ & S & $\mathrm{R}$ & $\mathrm{R}$ & $\mathrm{S}$ & $\mathrm{S}$ & S & $\mathrm{S}$ \\
\hline CD34 & Urine & blactX-м14 & blactX-м15 & & & $\mathrm{R}$ & $R$ & $\mathrm{~S}$ & $\mathrm{~S}$ & 1 & $\mathrm{~S}$ & $\mathrm{R}$ & I & I \\
\hline CD35 & Urine & blactX-M14 & & & & $\mathrm{R}$ & $\mathrm{R}$ & $\mathrm{S}$ & I & I & $\mathrm{R}$ & $\mathrm{R}$ & $\mathrm{S}$ & $\mathrm{S}$ \\
\hline CD36 & Urine & blactX-м14 & & & qnrs1 & $\mathrm{R}$ & $\mathrm{R}$ & $\mathrm{S}$ & $\mathrm{R}$ & I & $\mathrm{R}$ & $\mathrm{R}$ & $\mathrm{R}$ & $\mathrm{R}$ \\
\hline CD37 & Urine & blactX-м14 & blactX-м15 & & & $\mathrm{R}$ & $\mathrm{R}$ & I & $\mathrm{R}$ & I & $\mathrm{R}$ & $\mathrm{R}$ & $R$ & $\mathrm{R}$ \\
\hline CD38 & Urine & blactX-м14 & blactX-м15 & & & $\mathrm{R}$ & $R$ & $S$ & $\mathrm{R}$ & I & $\mathrm{R}$ & $\mathrm{R}$ & $\mathrm{R}$ & $\mathrm{R}$ \\
\hline CD39 & Urine & blactX-м14 & & & & $\mathrm{R}$ & $\mathrm{R}$ & $\mathrm{S}$ & $\mathrm{R}$ & I & $\mathrm{R}$ & $\mathrm{S}$ & $\mathrm{S}$ & $\mathrm{S}$ \\
\hline CD42 & Urine & blactX-м14 & & & & $\mathrm{R}$ & $\mathrm{R}$ & $S$ & $\mathrm{R}$ & I & $\mathrm{R}$ & $\mathrm{R}$ & $\mathrm{R}$ & $\mathrm{R}$ \\
\hline CD46 & Urine & blactX-м14 & blactX-м15 & & & $\mathrm{R}$ & $\mathrm{R}$ & I & I & 1 & $\mathrm{~S}$ & $\mathrm{R}$ & $\mathrm{R}$ & $\mathrm{R}$ \\
\hline CD49 & Urine & blactX-м14 & & & & $\mathrm{R}$ & $\mathrm{R}$ & $\mathrm{S}$ & $\mathrm{S}$ & 1 & $\mathrm{~S}$ & $\mathrm{R}$ & S & $\mathrm{S}$ \\
\hline CD50 & Urine & blactX-M14 & & & & $\mathrm{R}$ & $\mathrm{R}$ & $S$ & $\mathrm{R}$ & $S$ & $\mathrm{R}$ & $S$ & S & $\mathrm{S}$ \\
\hline CD53 & Urine & blactX-м14 & & $a a c 6-1 b-c r$ & & $R$ & $\mathrm{R}$ & $\mathrm{S}$ & $\mathrm{R}$ & I & $\mathrm{R}$ & $\mathrm{R}$ & $R$ & $\mathrm{R}$ \\
\hline CD55 & Urine & blactX-м14 & & $a a c 6-1 b-c r$ & & $\mathrm{R}$ & $\mathrm{R}$ & S & $S$ & I & $S$ & $S$ & S & $\mathrm{S}$ \\
\hline
\end{tabular}

Abbreviations: ESBL, extended-spectrum $\beta$-lactamase PMQR, plasmid-mediated quinolone resistance; AM, ampicillin; CTX, cefotaxime; CAZ, ceftazidime; NN, tobramycin; AK, amikacin; CN, gentamicin; NA, nalidixic acid; CIP, ciprofloxacin; LEV, levofloxacin; S, susceptible; $\mathrm{I}$, intermediate resistant, $\mathrm{R}$, resistant. 
Table 3. Antimicrobial susceptibilities of 25 CTX-M type ESBL producing Escherichia coli

\begin{tabular}{|c|c|c|c|c|c|c|c|c|c|}
\hline \multirow{3}{*}{ Agent } & \multicolumn{9}{|c|}{ Numbers (\%) of isolates } \\
\hline & \multicolumn{3}{|c|}{$\begin{array}{l}\text { E. coli containing } P M Q R \text { genes } \\
\qquad(n=12)\end{array}$} & \multicolumn{3}{|c|}{$\begin{array}{l}\text { E. coli not containing PMQR genes } \\
\qquad(\mathrm{n}=13)\end{array}$} & \multicolumn{3}{|c|}{$\begin{array}{l}\text { Total E. coli } \\
\quad(\mathrm{n}=25)\end{array}$} \\
\hline & S & 1 & $\mathrm{R}$ & S & । & $R$ & S & 1 & $R$ \\
\hline$A M$ & $0(0.0)$ & $0(0.0)$ & $12(100.0)$ & $0(0.0)$ & $0(0.0)$ & $13(100.0)$ & $0(0.0)$ & $0(0.0)$ & $25(100.0)$ \\
\hline CTX & $0(0.0)$ & $0(0.0)$ & $12(100.0)$ & $0(0.0)$ & $0(0.0)$ & $13(100.0)$ & $0(0.0)$ & $0(0.0)$ & $25(100.0)$ \\
\hline CAZ & $9(75.0)$ & $0(0.0)$ & $3(25.0)$ & $10(76.9)$ & $2(15.4)$ & $1(7.7)$ & $19(76.0)$ & $2(8.0)$ & $4(16.0)$ \\
\hline NN & $6(50.0)$ & $0(0.0)$ & $6(50.0)$ & $4(30.8)$ & $2(15.4)$ & $7(53.8)$ & $10(40.0)$ & $2(8.0)$ & $13(52.0)$ \\
\hline AK & $3(25.0)$ & $7(58.3)$ & $2(16.7)$ & $2(15.4)$ & $10(76.9)$ & $1(7.7)$ & $5(20.0)$ & $17(68.0)$ & $3(12.0)$ \\
\hline $\mathrm{CN}$ & $6(50.0)$ & $2(16.7)$ & $4(33.3)$ & $6(46.2)$ & $0(0.0)$ & $7(53.8)$ & $12(48.0)$ & $2(8.0)$ & $11(44.0)$ \\
\hline NA & $2(16.7)$ & $1(8.3)$ & $9(75.0)$ & $3(23.1)$ & $1(7.7)$ & $9(69.2)$ & $5(20.0)$ & $3(12.0)$ & $17(68.0)$ \\
\hline CIP & $3(25.0)$ & $0(0.0)$ & $9(75 . .0)$ & $6(46.2)$ & $1(7.7)$ & $6(46.2)$ & $9(36.0)$ & $1(4.0)$ & $15(60.0)$ \\
\hline LEV & $3(25.0)$ & $2(16.7)$ & $7(58.3)$ & $6(46.2)$ & $1(7.7)$ & $6(46.2)$ & $9(36.0)$ & $3(12.0)$ & $13(52.0)$ \\
\hline
\end{tabular}

Abbreviations: PMQR, plasmid-mediated quinolone resistance; AM, ampicillin; CTX, cefotaxime; CAZ, ceftazidime; NN, tobramycin; AK, amikacin; CN, gentamicin; NA, nalidixic acid; CIP, ciprofloxacin; LEV, levofloxacin; S, susceptible; I, intermediate resistant, R, resistant.

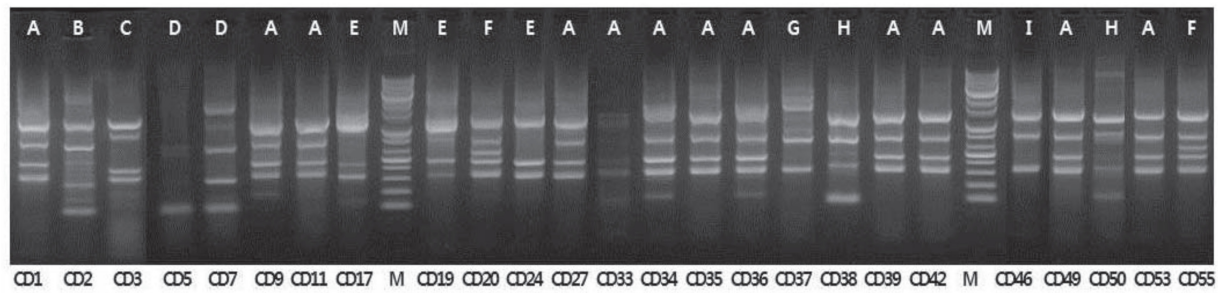

Fig. 1. Repetitive element sequence-based (REP)-PCR patterns of genomic DNA from twenty-five CTX-M type ESBL producing Escherichia coli isolates. Lane $M$ is $1 \mathrm{~kb}$ DNA size marker.
보였으며 그 중 4 균주는 두 개의 반응 모두에서 양성결과를 나타냈 다. 생성된 PCR 산물을 대상으로 유전형을 결정하기 위해 염기서 열분석을 실시한 결과 $q n r S$ 와 $a a d\left(6^{\prime}\right)-I b-c r$ 유전자 증폭산물은 각각 $q n r S 1$ 와 $a a d(6)-I b-C r$ 유전자로 확인되었다. 본 연구에서는 $q n r A, q n r B$, 및 qepA 유전자는 검출되지 않았다(Table 2).

\section{CTX-M형 ESBL 생성 대장균의 유전형 분석}

시험기간 중 분리된 25균주의 CTX-M형 ESBL 생성 대장균이 같은 클론에서 유래되었는지를 확인하기 위하여 REP-PCR을 수행 한 결과 총 9개의 band 패턴(A I형)이 확인되었다(Fig. 1). 그 중 A 형 band 패턴을 보인 균주가 12 균주로 가장 많았으며, $\mathrm{A}$ 형을 제외 한 나머지 8 개의 band 패턴(B I 형)을 나타낸 균주는 각각 3균주 이하였다.

\section{고 찰}

최근 들어 CTX-M형 ESBL의 종류가 급격하게 증가하고 있으며 CTX-M형 ESBL을 생성하는 세균 또한 전세계적을 빠르게 확산되 고 있는 추세에 있다. 국내에서도 CTX-M형 ESBL을 생성하는 대장 균이 빈번하게 분리되고 있는데 그 중에서도 CTX-M-14 또는
CTX-M-15 생성 대장균이 가장 많이 보고되고 있다[4,16]. 본 연 구에서도 수집된 대장균 156 균주 중 약 $16.0 \%$ 에 해당하는 25 균주 가 CTX-M형 ESBL을 생성하는 것으로 나타났다. 이 수치는 최근 국내에서 보고되고 있는 CTX-M형 ESBL을 생성하는 대장균의 비 율과 유사한 것으로 CTX-M형 ESBL이 국내에서 분리되는 대장균 에서 가장 빈번하게 검출되고 있는 $\mathrm{ESBL}$ 형임을 의미한다[17]. 한 편, 일반적으로 CTX-M형 ESBL은 ceftazidime 보다는 cefotaxime 을 더 효과적으로 분해하는 것으로 알려져 있다. 본 연구에서도 CTX-M형 ESBL을 생성하는 대장균 25균주가 cefotaxime에는 모 두 내성을 보인 반면 ceftazidime에는 $76.0 \%$ 가 감수성을 나타냈다.

$\mathrm{PMQR}$ 유전자는 quinolone 계열의 항균제에 대해 낮은 수준의 내성을 나타냄에도 불구하고 ESBL 유전자와 마찬가지로 mobile genetic elements를 통해 다른 세균으로 전파될 수 있어 내성확산 의 우려가 있다. 본 연구에서도 CTX-M형 ESBL을 생성하는 대장균 중 48\% (12균주)가 $\mathrm{PMQR}$ 유전자를 가지고 있는 것으로 나타났다. 특히 DNA gyrase를 보호하는 단백을 암호화하는 qnrS1 유전자를 포함하는 대장균이 $32 \%$ (8균주)나 되었다. 이전의 중국과 국내에 서 분리된 ciprofloxacin 내성 대장균을 대상으로 한 연구에서는 각각 $7.5 \%$ 와 5.6\%에 해당하는 대장균만이 $q n r$ 유전자를 가지고 있 는 것으로 보고한 바 있다[7]. 본 연구에서 $q n r$ 유전자의 분리빈도 
가 월등하게 높았던 것은 CTX-M형 ESBL을 생성하는 대장균을 대 상으로 조사했기 때문인 것으로 사료되며 이는 $q n r$ 유전자가 CTX-M형 ESBL 유전자와 연관되어 있음을 시사한다. 한편, 이전 의 연구자들은 대장균에서 $a a c(6)-I b-c r$ 유전자의 검출빈도는 높 은 편으로 미국의 경우 $32 \%$ 의 대장균이 그리고 국내의 경우 $\mathrm{ESBL}$ 생성 대장균의 $34.1 \%$ 가 $\operatorname{aac}\left(6^{\prime}\right)-I b-c r$ 유전자를 포함하고 있다고 하였다[7]. 본 연구에서도 quinolone 계열의 항균제를 변형시켜 항 균제의 기능을 못하게 하는 $a a d\left(6^{\prime}\right)-I b-c r$ 유전자를 포함하는 대 장균이 $32 \%$ (8균주)로 이전의 보고와 유사한 결과를 나타냈다. $\mathrm{PMQR}$ 유전자는 fluoroquinolone 항균제에 비록 낮은 수준의 내 성을 나타내지만 치료를 위한 항균제의 선택압력에 놓일 경우 높은 농도에도 내성을 유발할 수 있다고 보고되고 있다[18,19].

본 연구에서는 충청지역에 위치한 일개의 대학병원에서 분리된 대장균을 대상으로 $\mathrm{ESBL}$ 및 $\mathrm{PMQR}$ 유전자의 빈도와 유전형을 조 사하였다. 충청지역에서 분리된 대장균은 상당히 높은 빈도로 ESBL 및 PMQR 유전자를 포함하고 있었다. ESBL 및 PMQR 유전자 는 빈번하게 mobile genetic elements를 통해 세균간에 확산되어 다재내성 세균의 출현을 야기할 수 있다. 게다가 CTX-M형 ESBL 생성 대장균의 $48 \%$ (12균주)가 같은 클론에서 유래되었음을 REP-PCR을 통해 확인할 수 있었는데 이는 CTX-M형 ESBL 생성 대장균이 수평확산 되었음을 의미한다. 따라서 다제내성 세균의 출 현 및 확산을 방지하기 위해서는 지속적인 항균제 내성유전자에 대 한 조사와 모니터링이 필요할 것으로 사료된다.

\section{요 약}

최근 들어 CTX-M형 extended-spectrum $\beta$-lactamase (ESBL) 생성 대장균이 국내는 물론 전세계적으로 빠르게 증가하고 있다. 본 연구에서는 충청지역에 위치한 일개의 대학병원에서 분리 된 대장균을 대상으로 $\mathrm{ESBL}$ 유전자를 중합효소연쇄반응 및 염기서 열 분석방법을 통해 확인하였으며, 같은 방법으로 $\mathrm{ESBL}$ 생성 대장 균으로부터 plasmid mediated quinolone resistance (PMQR) 유 전자의 빈도를 조사하였다. $16.0 \%$ 에 해당하는 25 균주가 CTX-M-14 를 생성하였으며 이중 9균주는 CTX-M-15도 동시에 생성하는 것 으로 나타났다. 항균제 감수성 시험결과 CTX-M형 ESBL을 생성하 는 대장균은 모두 cefotaxime에 내성을 보였다. 한편 CTX-M형 $\mathrm{ESBL}$ 을 생성하는 대장균의 $48 \%$ (12균주)가 $\mathrm{PMQR}$ 유전자를 포함 하고 있음이 확인되었는데 8균주가 qnrS1유전자를 그리고 8균주 가 $\operatorname{aac}\left(6^{\prime}\right)-I b-c r$ 유전자를 포함하고 있었다. 그 중 4균주는 두 개 의 유전자를 모두 가지고 있는 것으로 나타났다. 본 연구에서는 플 라스미드를 통해 확산될 수 있는 ESBL 및 PMQR 유전자가 대장균
사이에 확산되어 있음을 확인하였다. 항균제 내성유전자들의 확산 을 막기 위해서는 지속적인 내성유전자의 모니터링과 감시가 필요 할 것으로 사료된다.

\section{Acknowledgements: None}

Funding: None

Conflict of interest: None

\section{References}

1. Qadri F, Svennerholm AM, Faruque AS, Sack RB. Enterotoxigenic Escherichia coli in developing countries: epidemiology, microbiology, clinical features, treatment, and prevention. Clin Microbiol Rev. 2005;18:465-483.

2. Canton R, Gonzalez-Alba JM, Galan JC. CTX-M enzymes: origin and diffusion. Front Microbiol. 2012;3:110.

3. Poirel L, Kampfer P, Nordmann P. Chromosome-encoded Ambler class A beta-lactamase of Kluyvera georgiana, a probable progenitor of a subgroup of CTX-M extended-spectrum beta-lactamases. Antimicrob Agents Chemother. 2002;46:40384040.

4. Song W, Lee H, Lee K, Jeong SH, Bae IK, Kim JS, et al. CTX-M-14 and CTX-M-15 enzymes are the dominant type of extended-spectrum beta-lactamase in clinical isolates of Escherichia coli from Korea. J Med Microbiol. 2009;58: 261-266.

5. Seo MR, Park YS, Pai H. Characteristics of plasmid mediated quinolone resistance genes in extended-spectrum cephalosporin-resistant isolates of Klebsiella pneumoniae and Escherichia coli in Korea. Chemotherapy. 2010;56:46-53.

6. Ruiz J. Mechanisms of resistance to quinolones: Target alterations, decreased accumulation and DNA gyrase protection. J Antimicrob Chemother. 2003;51:1109-1117.

7. Yang HY, Nam YS, Lee HJ. Prevalence of plasmid-mediated quinolone resistance genes among ciprofloxacin-nonsusceptible Escherichia coli and Klebsiella pneumoniae isolated from blood cultures in Korea. Can J Infect Dis Med Microbiol. 2014;25:163-169.

8. Robicsek A, Strahilevitz J, Jacoby GA. Fluoroquinolone modifying enzyme: A new adaptation of a common aminoglycoside acetyltransferase. Nat Med. 2006;12:83-88.

9. Bae IK, Kim J, Sun JY, Jeong SH, Kim YR, Wang KK, et al. Comparison of pulsed-field gel electrophoresis \& repetitive sequence-based PCR methods for molecular epidemiological studies of Escherichia coli clinical isolates. Indian J Med Res. 2014; 140:679-685.

10. CLSI. Performance standards for antimicrobial susceptibility testing; sixteenth informational supplement. CLSI document M100-S20. Wayne, PA: Clinical and Laboratory Standards Institute; 2010, p52-53.

11. Lewis JS, Herrera M, Wickes B, Patterson JE, Jorgensen JH. First report of the emergence of CTX-M-type extended-spectrum beta-lactamases (ESBLs) as the predominant ESBL isolated in a 
U.S. health care system. Antimicrob Agents Chemother. 2007; 51:4015-4021.

12. Cattoir V, Poirel L, Rotimi V, Soussy CJ, Nordmann P. Multiplex PCR for detection of plasmid-mediated quinolone resistance qnr genes in ESBL-producing enterobacterial isolates. J Antimicrob Chemother. 2007;60:394-397.

13. Song S, Lee EY, Koh EM, Ha HS, Jeong HJ, Bae IK, et al. Antibiotic resistance mechanisms of Escherichia coli isolates from urinary specimens. Korean J Lab Med. 2009;29:17-24.

14. Yamane K, Wachino J, Suzuki S, Arakawa Y. Plasmid-mediated qepA gene among Escherichia coli clinical isolates from Japan. Antimicrob Agents Chemother. 2008;52:1564-1566.

15. Bou G, Cerveró G, Domínguez MA, Quereda C, MartínezBeltrán J. PCR-based DNA fingerprinting (REP-PCR, AP-PCR) and pulsed-field gel electrophoresis characterization of a nosocomial outbreak caused by imipenem- and meropenem-resistant Acinetobacter baumannii. Clin Microbiol Infect. 2000; 6:635-643.
16. Sung JY, Oh JE, Kim ES, Son JM, Kim HY, Lim DY. Spread of CTX-M Extended-spectrum $\beta$-lactamase Producing Escherichia coli in the Community in Chungcheong Area, Korea. Korean J Clin Lab Sci. 2013;45:43-47.

17. Kim JS, Kim J, Kim SJ, Jeon SE, Oh KH, Cho SH, et al. Characterization of CTX-M-type extended-spectrum beta-lactamase-producing diarrheagenic Escherichia coli isolates in the Republic of Korea during 2008-2011. J Microbiol Biotechnol. 2014;24:421-426.

18. Nordmann P. In vivo selection of fluoroquinolone-resistant Escherichia coli isolates expressing plasmid-mediated quinolone resistance and expanded-spectrum beta-lactamase. Antimicrob Agents Chemother. 2006;50:1525-1527.

19. Kim S, Sung JY, Choi SG. Molecular Characterization of Escherichia coli Isolates from Humans and Chickens in the Chungcheong Area Using MLST Analysis. Korean J Clin Lab Sci. 2015;47:71-77. 